\title{
Do People's Perceptions of Change have an Influence on the Status of Change? Lessons from the Department of Correctional Services of South Africa
}

\author{
Mbongeni A. Mdletye \\ Jos Coetzee \\ Wilfred I. Ukpere \\ Department of Industrial Psychology and People Management, Faculty of Management \\ University of Johannesburg, Johannesburg, South Africa \\ E-mail: wiukpere@uj.ac.za, mbongeni@telkomsa.net
}

\section{Doi:10.5901/mjss.2014.v5n4p32}

\begin{abstract}
Organisational change is one of the most critical challenges that leaders in organizations have to contend with. There is an urgent need for change strategists, change implementers, and change recipients to be assisted with new or updated knowledge on change and organisational change. There is a high failure rate in the implementation of organisational change interventions and this points to the fact that there is a problem with the current organisational change management methodologies. The starting point in reversing the trend of high failure rate in the implementation of organisational change interventions is to create a deeper understanding of organisational change (Puplampu, 2005; Smollan. 2006; Van Tonder, 2008, 2009). This new understanding should focus, amongst other things, on how change is perceived at individual level, and how perceptions influence the status of change in terms of success or failure (Judge, Thoresen, Pucik \& Welbourne, 1999; George \& Jones, 2001; Van Tonder, 2004b, 2005, 2006, 2009). This is what this study sought to do - to investigate, establish, explore and understand the extent to which peoples' perceptions are related to the status of change in terms of success or failure. Empirical studies that seek to validate the claim of relatedness of people's perceptions of change to the status of change are somehow limited. The researchers conducted a literature study in order to contextualise the relatedness of perceptions of change to the status of change within the offender correctional environment in the Department of Correctional Services of South Africa. Two survey questionnaires, one for correctional officials and the other for offenders, were utilised for purposes of collecting data. The results of the study revealed that perceptions of change are related to the status of change.
\end{abstract}

Keywords: Change, organisational change, transformational change, change management, perceptions, status, emotional reaction, experiences, resistance

\section{Introduction and Background}

Organisations throughout the world are undergoing changes at an ever-increasing rate (Burnes, 2004; Imberman, 2009; Kohurt, 2010; Agboola \& Salawu, 2011; Turner, 2011) due to the changing and increasing needs of customers; deregulation, the globalisation of the economy, increasing competition due to globalisation, the need to control costs and increase efficiency, and the fast pace of technological innovations (Cook, Macaulay \& Coldicott, 2005; Corbeau \& Sijats, 2005; Palmer, Dunford \& Akin, 2009; Kohurt, 2010; Turner, 2011). Despite the increasing prevalence and intensifying pace of change in organisations as a result of the factors highlighted above, organizations are not at all succeeding in implementing and institutionalising change initiatives effectively (Mourier \& Smith, 2001; Balogun \& Hope Hailey, 2004; Bregman, 2009; Lotich, 2011; Choi \& Ruona, 2011). The poor success rate in the implementation of organisational change initiatives points to the existence of serious challenges regarding the process of institutionalising and sustaining changes in organisations. According to Anderson and Ackerman Anderson (2012), one of the reasons for the high failure rate in implementing change efforts is that change leaders implement changes faster than employees can adapt.

Empirical studies indicate that the failure rate in the implementation of organisational change initiatives varies between 65\% and 75\% (Beer \& Nohria, 2000; Mourier \& Smith, 2001). Nguyen and Kleiner (2003) and Balogun and Hope Hailey (2004) point to a high failure rate of approximately $70 \%$ regarding the organizational change initiatives that are implemented. The mergers and acquisitions survey conducted by KPMG points to an 83\% failure rate (Hattingh, 2004). Van Tonder (2004a; 2006) emphasises that despite the many change efforts implemented in organisations, 
organisations continue to record dismal change success rates. Recent studies point to the fact that the situation is not improving (Coetzee \& Stanz, 2007; Alvesson \& Svenningsson, 2008; Aiken \& Keller, 2009; Turner, Hallencreutz \& Haley, 2009; Turner, 2011). There is absolutely no sustained change (Choi \& Ruona, 2011). The low success rate indicates the magnitude of the challenge facing managers within the realm of organisational change management.

The dismally low success rates recorded for change implementation suggest that the traditional approach for pursuing organisational change initiatives are not effective. It does not yield the desired results. This suggests that the approaches currently utilized to deal with and resolve novel change-type challenges that arise in organisations are no longer useful. The current approaches to change management negate the intrapersonal dynamics of perceiving and responding to organizational change (Van Tonder, 2006). The inadequate attention by managers to the human dimension of organisational change gives rise to the high failure rate in the implementation of organisational change interventions (Devos, Beulens \& Bouckenooghe, 2007; Rodda, 2007; Smith, 2009; Social Media Directory, 2011). This assertion suggests that the neglect of the human elements and dynamics of transformational change is behind the high failure rate in the implementation of transformational change initiatives. Therefore, it means that managers need to attend to the human dimension of change, and addressing the human side of change means looking at how employees perceive organisational change and at the impact that people's perceptions have on the status of change. This is also important because it is employees' change perceptions (positive or negative) that determine employees' responses to change in terms of emotional reactions (positive or negative experiences) and resistance to change and consequently the status of change.

What is also important and needed is for organisations to develop the necessary capacity to better manage the changes they introduce as a result of their desires and aspirations for more growth, more productivity, and more success. This is the challenge which all organisations must deal with. As long as organisations do not have the required managerial capacity to ensure effective management of changes, organisations will continue to experience a high failure rate when it comes to the implementation of change initiatives (Balogun \& Hope Hailey, 2004; Todnem, 2007; Alvesson \& Svenningsson, 2008; Aiken \& Keller, 2009; Turner, 2011). This high failure rate indicates how low the success rate is in terms of the implementation of organisation-wide changes and how big the challenge is in terms of change management.

Organisational change scholars, change strategists, change agents, and change implementers require more empirical evidence that will point to the importance of, or the role that the human factor plays in the implementation of organisational change initiatives. Currently, there is limited empirical evidence on the contribution of the human factor to the success or failure of organisational change initiatives (Briner \& Kiefer, 2005; Van Tonder, 2006). And as such, there is an urgent need to discover the role played by the dynamics of people's perceptions of, and responses to, organisational change.

It has been established empirically, through establishing, exploring and understanding correctional officials' and offenders' perceptions and emotional reactions to the experiences of transformational change, that the human element plays a critical role in the implementation of organisational change initiatives. People's perceptions of organisational change play a significant role in the success or failure of change efforts (Decker, Wheeler, Johnson \& Parsons, 2001). They can either facilitate or undermine the effectiveness of organisational change initiatives (Vas \& Lejeune, 2004). This suggests that employees' perceptions do influence the direction of organisational change in terms of success or failure. This further implies that the success of organisational change interventions is inextricably linked to employees' perceptions. Furthermore, perception, as a psychological phenomenon, plays a significant role in the individual experience of change. The perception of, and the meaning attributed to, the change should be the key factor or consideration in the experience of change (Van Tonder, 2004a).

Everyone responds to change differently and these different responses are influenced by different perceptions of change. These different perceptions of change may be either positive or negative. Positive perceptions arise when an employee views change as enhancing, exciting, strengthening, and giving; while negative perceptions of change arise when a person perceives change as threatening, confusing, hurting, taking something valuable from the employee, and defeating. For this reason, the success of any organizational change effort is determined by employees' perceptions of, and subsequently their attitudes towards, the change effort. Hence the varying perceptions of organizational change lead to different experiences of organizational change which, in turn, lead to different change outcomes - success or failure (Refferty \& Griffin, 2006; Ursiny \& Kay, 2007)

\subsection{Problem statement}

The high failure rate in change implementation, which can be traced to managers' neglect of the human dimension of 
transformational change, and which is compounded by organizational change strategists' and change implementers' lack of technical expertise on the human dimension of change, is a result of the lack of knowledge due to limited empirical research on the subject. This reflects the magnitude of challenges facing organisations' implementation of transformational change initiatives.

\subsection{Objectives}

The objectives of this paper are:

- To explore the relatedness of people's perceptions to the status of change;

- To determine the influence of perception of change as an exogenous variable on the status of change as an endogenous variable;

- To highlight the strength and statistical significance of the relationship between perception of change and status of change;

- To emphasize the importance of managers in establishing, addressing and mitigating people's perceptions of change, as well as the effect of perceptions of change on the status of change;

- To emphasise the importance of decisive managerial intervention and action in mediating people's negative perceptions of change in order to limit negative emotional reactions to change and the consequent resistance to change; and

- To generally highlight and emphasise the importance, on the part of change agents and change implementers, of managing the human dimension of change so as to ensure that the human element does not impact negatively on the organisational change process.

\section{Literature Study on the Relationship between the Perception of Change and the Status of Change}

Both the organisation and change are all about people. Imberman (2009) emphasises that people, as members of organisations, are not passive to organisational change initiatives. Organisations are made up of people who, as individuals, perceive and experience change on a personal level (Kohurt, 2010). Agboola and Salawu (2011) emphasise that people are the primary inhibitors of change in all organisations across the business spectrum. People's perceptions play a significant role in determining their reactions to the change in terms of whether they will support the change or be opposed to it (Judge, Thoresen, Pucik \& Welbourne, 1999; George \& Jones, 2001; Van Tonder, 2004b, 2005, 2006, 2009). Given people's emotional reactions to the change (support for the change underpinned by positive emotions, or opposition to the change as exhibited by negative emotions) (Kiefer \& Briner, 2006), perceptions do play a role in influencing the direction of the change - for the better (success) or for the worse (failure) (Wharton Executive Education, 2008). Negative perceptions of change, which lead to negative emotional reactions to, and negative experiences of, change, contribute to opposition and resistance to change (Van Tonder, 2004b), and consequently the failure of organizational change efforts. On the other hand, positive perceptions of change, which lead to positive emotional reactions to, and positive experiences of, change, contribute to support for, and facilitation of, change (Van Tonder, 2004b), and consequently the success of organisational change efforts.

People, irrespective of their position or status in organizations, are affected by the change (Van Tonder, 2004a). And because they are affected by the change, they perceive the change differently in terms of their needs, wishes and expectations. It is these perceptions that shape the direction of the change - success or failure of the change. According to Agboola and Salawu (2011), positive perception of change based on the perceived positive benefits of change promotes commitment to, and support for, the change. Negative perceptions of change as informed by the perceived negative effects of change, which generates opposition to change, and ultimately lead to resistance to change (Agboola \& Salawu, 2011).

The foregoing argument suggests that perceptions inform people's interpretation and understanding of organisational change and as such, perceptions shape people's behaviors and attitudes, be they negative or positive, towards organizational change. Because perceptions shape people's behaviors and attitudes towards organisational change, perceptions play a role in evoking behavioral response to organisational change. This behavioral response is two-pronged: positive behavioral response, which points to people's approval of and support for change and negative behavioral response, which indicates people's disapproval of and objection to change. The negative behavioral response to organisational change leads to people's resistance to change, which Plant (1987), Eby \& Adams (2000) and Vas \& Lejeune (2004) refer to as behavioral resistance to organisational change and which is underpinned by perceptions, 
reactions and assumptions of individual people or groups of people within the organization. It is also in the same vein that Eby \& Adams (2000) and Vas \& Lejeune (2004) consider people's perceptions as playing a critical role in the process of organisational change and accordingly in the creation of resistance to change. On the side of negative attitudes towards organisational change, one may emphasise that negative perceptions of organisational change serve to fuel people's resistance to change. For this reason, negative perceptions derail the organisational change process. If negative perceptions derail the organisational change process, it means that negative perceptions lead to the failure of organisational change efforts. Out of this assertion the following theoretical perspective emerges:

There is a positive causal relationship between people's negative perceptions of organisational change and the failure (status) of organisational change.

The above perspective suggests that negative perceptions cause the failure of organisational change efforts as people resist the change. On the side of positive attitudes towards organisational change, one may point out that positive perceptions of organizational change serve to promote and facilitate the implementation of change initiatives. For this reason, positive perceptions facilitate the implementation of organisational change geared towards the attainment of the desired change outcomes. If positive perceptions promote organizational change, it means that positive perceptions lead to the success of organisational change efforts. Out of this assertion the following theoretical perspective emerges:

There is a positive causal relationship between people's positive perceptions of organisational change and the success of organisational change.

The above perspective suggests that positive perceptions lead to the successful implementation of organisational change efforts as people support the change.

The above-named two theoretical perspectives further point to the following:

The existence of a positive causal relationship between people's perceptions of organisational change (be they negative or positive) and the status of organisational change (in terms of success or failure).

As Decker, Wheeler, Johnson \& Parsons (2001) put it, the perceptions of employees play a critical role in the success of any organisational change process. Therefore, it becomes necessary for organizational change scholars, change strategists, change agents, and change implementers to focus more on establishing how employees' perceptions influence the status of organisational change.

\section{Methodology}

This study utilised a two-pronged research approach, which encompassed a literature study and a quantitative empirical study. Methodologically, the study applied a mixed approach in that three types of research designs, namely the exploratory design, the survey design, and descriptive design were utilised.

\subsection{Sample, sampling method and population}

A random, purposive and probability samples of 1000 and 500 out of 7593 correctional officials and 13520 offenders respectively in the KwaZulu-Natal Region of the Department of Correctional Services of South Africa were utilised.

\subsection{Research procedure}

The procedure followed in the execution of this empirical study entailed conducting a pilot study, administering the research instruments, and scoring the responses. The empirical data was collected by means of two survey questionnaires, one for correctional officials and the other for offenders. A 5-point Likert type response scale was utilized in the two questionnaires to measure correctional officials' and offenders' perceptions of transformational change.

\subsection{Response rate}

The return rate of $71.3 \%$ and the frequency rate of $98.2 \%$ for valid responses were recorded for correctional officials. For the offenders' sample, the return rate of $58.2 \%$ and the frequency rate of 97.6 for valid responses were recorded. 


\subsection{Structural integrity of measuring instruments}

Face validity: The inspection of the individual items on both questionnaires reveals high face validity. Content validity: The contents of the questionnaire are relevant to the research question dealing with the relatedness of correctional officials' and offenders' perceptions of the DCS change to the status of the DCS change. Construct validity: Based on results of face validity and content validity, it can be concluded that the two questionnaires utilized in the study measured what they were designed to measure in terms of the relatedness of correctional officials' and offenders' perceptions of the DCS change to the status of the DCS change.

\subsection{Reliability analysis}

Two statistical techniques are most commonly used to help assess the appropriateness of data for factorability, namely, the Kaiser-Meyer-Olkin (KMO) measure of sampling adequacy (Kaiser, 1970) and the Bartlett's test of sphericity (Bartlett, 1954). Therefore, in the case of this study, the suitability of data for factor analysis was assessed using the KMO measure of sampling adequacy and the Barlett's test for sphericity. A result of 0.6 and higher is always required from the measure of sampling adequacy (MSA) for it to be acceptable for factor analysis purposes (Hair, Anderson, Tatham, \& Black, 2003; Hair, Anderson, Tatham \& Black, 2006; Tabachnick \& Fidell, 2007). The KMO MSA value for the perception of DCS change variable in respect of correctional officials was .942, which is highly significant because it is well above 0.6 recommended value. The results of the assessment of the suitability of data for factor analysis pointed to the fact that the data sets in respect of correctional officials complied with the requirements of sampling adequacy and sphericity and could thus be subjected to factor analysis.

For the offender variables, the data sets complied with the requirements of sampling adequacy and sphericity. The KMO MSA value obtained for the perception of DCS change variable was .855, which indicates high significance. The $\mathrm{KMO}$ value exceeded the recommended cut-off value of 0.6 (Hair et al., 2006). Lastly, the Bartlett's test of sphericity values (that is, Sig. values) should be .05 or smaller. Therefore, it is significant to note that the Bartlett's test values for both correctional officials and offenders reached statistical significance $(p=0.000)$, thereby supporting the factorability of the correlation matrices.

Using the KMO MSA and Barlett's sphericity test results, it was further concluded that both questionnaires used in the study had a good content validity because they covered all the major aspects of the content that are relevant. Since the data sets were found to be suitable for factoring, factor analysis was conducted through exploratory factor analysis techniques. The extraction method utilized was the Principal Component Analysis (PCA), and the rotation method used was the Direct Oblimin with Kaiser Normalisation. The statistics reflects a Cronbach alpha coefficient of .950 from 32 items for the perception and experience of the DCS change; .854 from 11 items for the perceived nature of the DCS change (type if change); and .893 from 18 items for the perceived impact of the DCS change on the DCS as an organization from the perspective of correctional officials. For the offenders, Table 5 shows a Cronbach alpha coefficient of . 815 from 10 items for the perception and experience of the DCS change; .774 from 8 items for the perceived nature of the DCS change (type if change); and .842 from 13 items for the perceived impact of the DCS change on the DCS as an organization. From Tables 4 and 5, it is significant to note that the Cronbach alpha coefficients indicate that the two measuring instruments have acceptable reliability and consistency in terms of measuring the perception of the DCS change that they were designed to measure.

\section{Data Analysis and Discussion of Findings}

\subsection{Relationship between the perception of the DCS change and the status of the DCS change}

The hypothesised structural models captured below (Figures 1 and 2) postulate that there is a relationship between the perception of the DCS change and the status of the DCS change. The structural model hypothesises a relationship in which the perception of the DCS change (as a predictor or exogenous or independent variable) influences or causes changes in the status of the DCS change (as an outcome or endogenous or dependent variable). The relationship between the perception of the DCS change and the status of the DCS change is viewed from the perspective of both correctional officials and offenders. 


\subsubsection{Correctional officials' perceived relationship between the perception of the DCS change and the status of the DCS change}

The perceived relationship between the perception of the DCS change and the status of the DCS change by correctional officials is symbolized by the graphical representation captured below (Figure1). The graph indicates or postulates that there exists a relationship between the correctional officials' perception of the DCS change and the status of the DCS change. This is a causal relationship in which the perception of the DCS change influences or causes a change in the status of the DCS change (the one-headed arrow from the perception of the DCS change into the status of the DCS change indicates this causal relationship). The graphical representation also entails the latent factors associated with both the exogenous variable (the perception of the DCS change) and the endogenous variable (the status of the DCS change) and how these factors are interrelated.

The following table indicates standardised estimates which summarise the relationship between the status of the DCS change (represented by two factors - F1 and F2) and the perception of the DCS change (represented by two factors as well - F3 and F4).

Table 1 Standardized Estimates: Relationship between the Perception of DCS Change and the Status of DCS Change Correctional Officials

\begin{tabular}{|l|c|c|}
\hline \multicolumn{2}{|c|}{ Factors } \\
\hline & $\begin{array}{c}\text { Factor 3 (Perception and } \\
\text { experience of the DCS change) }\end{array}$ & $\begin{array}{c}\text { Factor 4 (Perceived nature of } \\
\text { the DCS change) }\end{array}$ \\
\hline $\begin{array}{l}\text { Factor 1 (Perceived effectiveness of correctional } \\
\text { centres as rehabilitative institutions) }\end{array}$ & .382 & -.103 \\
\hline $\begin{array}{l}\text { Factor 2 (Orientation towards [treatment of) } \\
\text { offenders) }\end{array}$ & -.246 & +.091 \\
\hline
\end{tabular}

Note: 1. Correlation scale (Table 5.19) used to determine the existence of a relationship.

2. The value of standardized estimates used to determine the magnitude of the relationship.

3. The null hypothesis is that the correlation coefficient is equal to zero $(r=0)$.

4. The alternative hypothesis is that the correlation coefficient is greater than zero $(r>0)$.

5. The larger the coefficient of an IV, the larger the observed influence on the DV.

If one utilises the correlation scale referred to above (Table 1), one gets a sense that the standardised estimates captured in the foregoing table indicate that there is a relationship between both factors of the exogenous variable and both factors of endogenous variable. This relationship, in terms of the coefficients, ranges in terms of the magnitude from very low/small correlation to low/small correlation through to moderate correlation. The higher the correlation coefficient, the stronger the relationship. And the lower the coefficient, the smaller or weaker the relationship (Guilford (cited in Tredoux \& Durrheim, 2002; Saurina \& Coenders, 2002; Gall, Gall \& Borg, 2003). For example, the value of .382 represents a moderate relationship, while the value of -.246 denotes a low relationship. Regarding the direction of the relationship, the plus or minus sign points to the direction of the relationship. In terms of the coefficients, the direction of the relationships assumes both a positive direction (e.g., .382 between factor 1 and factor 3 ) and a negative direction (e.g., -.246 between factor 2 and factor 3) (Upton \& Cook, 2006). The value of .382 in this case points to a positive relationship/association between two factors, namely the perceived effectiveness of correctional centers as rehabilitative institutions (F1) and perception and experience of the DCS change (F3). On the other hand, the value of -.246 denotes a negative relationship between orientation towards (and treatment of) offenders (F2) and the perceived nature of the DCS change (F4). These two relationships can be graphically represented as follows:

Figure 1: Relationship between F1 and F3

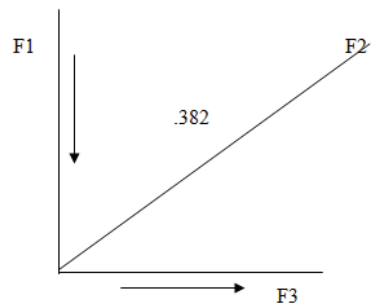


Figure 2: Relationship between F2 and F3

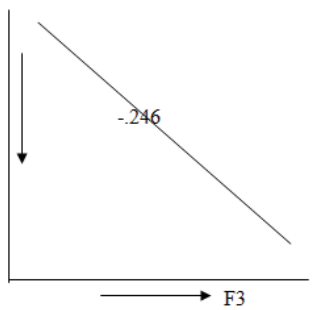

The following graph depicts the relationships among the two factors constituting the perception of the DCS change on one side, and the two variables constituting the status of the DCS change on the other.

Figure 3: Relationships among Latent Factors: Perception and Status of the DCS Change (Correctional Officials)

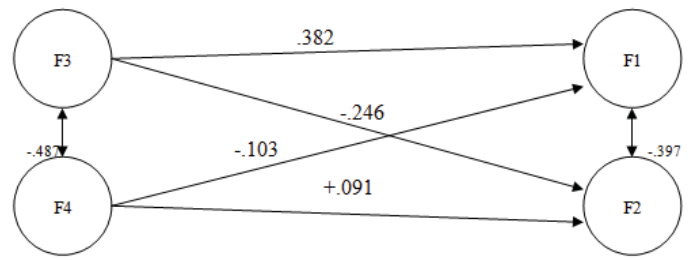

\subsubsection{Strength or magnitude of the relationship}

The relationship between perc-exp (latent variable of the perception of DCS change exogenous variable and perc-eff (latent variable of the status of the DCS change endogenous variable) is moderate and reliable $(r=.382)$. The relationship between perc-exp and ori-treat (the latent variable of the status of DCS variable is weak/small or low $(r=$ .246). On the other side, the relationship between perc-nat on one hand, and perc-eff and ori-treat on the other, is very weak/small or low ( $r=.091$ and -.103 respectively). This suggests that the perception of the nature of change latent variable has less influence/effect on the status of change latent variables than the perception and experience of change latent variable, which exerts the most influence/effect on the status of change latent variables as a result of the moderate link between them. This is despite the fact that there is a strong linear link between the perception and experience of change and the perception of the nature of change in terms of correlation coefficient (-.487) and covariance coefficient (.512).

\subsubsection{Statistical significance}

With regard to the statistical significance of the relationship between the perception of the DCS change and the status of the DCS change from the perspective of correctional officials, the relationship between perc-exp latent variable on one hand, and the perc-eff and ori-treat latent variables on the other, was found to be statistically significant $(p=2.780$ and $t$ $=-2.585)$ and $(p=4.368$ and $t=4.129)$. On the other hand, the relationship between the perc-nat latent variable on one hand, and the perc-eff and ori-treat latent variables on the other, has been found to be statistically insignificant $(p=1.110$ and $t=1.112)$ and $(p=-1.381$ and $t=-1.360)$. Therefore, the null hypothesis that there is no statistically significant relationship between the exogenous variables and the endogenous variables does not wholly hold in this case based on the fact that the relationship between the perception and experience of change latent variable (of the perception of the DCS change exogenous variable) and the perceived effectiveness of correctional centers as institutions of rehabilitation and the orientation towards (and treatment of) offenders latent variables has been found to be statistically significant. In this case, the null hypothesis is rejected in favour of the alternative hypothesis that there is a statistically significant relationship between the exogenous variable (i.e. perception of the DCS change) and the endogenous variable (i.e. the status of the DCS change). This means that the two latent variables of the exogenous variable have an effect on the endogenous variable such that there is a noticeable variation in the endogenous variable as a result of the influence of 
the exogenous variable.

Figure 4: Structural Model for Correctional Officials: Perception of the DCS Change and the Status of the DCS Change

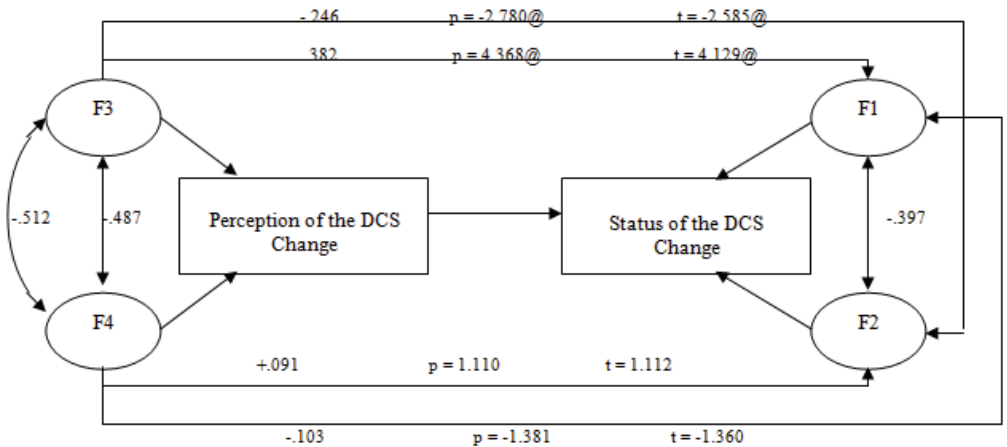

Note:

1. $\quad F 1=$ Perc-eff; $F 2=$ Ori-treat; $F 3=$ Perc-exp; F4 = Perc-nat.

2. Correlations significant at $p>01(t>2.56)$ or $p>05(t>1.96)$.

The higher the correlation, the better the reliability.

3. A correlation of zero means that one variable cannot be predicted from the other without a large error.

4. The null hypothesis is equal to zero.

5. The alternative hypothesis is greater than zero.

6. A large correlation coefficient is significant.

7. Non-significant correlation means meaningless prediction of one variable from the other.

8. Significant correlation below .7: real but weak relationship with much error of prediction.

9. Significant correlation above .7: strong relationship with moderate error of prediction.

10. Significant correlation above .9: very strong relationship with good accuracy of prediction.

11. Reject null hypothesis if $p$-value is less than significance level $(p<t)$.

(Upton \& Cook,

12. A small t-value and a big $p$-value means that there is no significant difference between null hypothesis and alternative hypothesis - non-significant relationship.

13. A big t-value and a small p-value means that there is significant difference between null hypothesis and alternative hypothesis - significant relationship.

14. Curved double-headed arrow represents covariation between the two latent variables.

15. Straight double headed arrow represents correlation between the two latent variables.

The above diagram indicates that there are relationships among the two latent factors of the perception of the DCS change on one hand, and the two latent factors of the status of the DCS change on the other. These results do suffice as an indication of the existence of a causal relationship between the perception of the DCS change and the status of the DCS change as exogenous and endogenous variables respectively.

\subsubsection{Offenders' perceived relationship between perception of the DCS change and the status of the DCS change}

The perceived relationship between the perception of the DCS change and the status of the DCS change by offenders is graphically represented below (Figure 5). The graph postulates a relationship between offenders' perception of the DCS change on one hand, and the status of the DCS change on the other. This is a causal relationship in which the perception of the DCS change influences or causes a change in the status of the DCS change (the one-headed arrow from the perception of the DCS change into the status of the DCS change indicates this causal relationship). The graph also entails latent factors that are associated with both the predictor variable (the perception of the DCS change) and the outcome variable (the status of the DCS change) and how these factors are to each other.

The table captured below sketches out standardized estimates which summarize the relationship between the status of the DCS change (represented by two factors - F6 and F7) and the perception of the DCS change (also represented by two factors as - F4and F5). 
Table 2: Standardized Estimates: Relationship between the Status of the DCS Change and the Perception of the DCS Change - Offenders

\begin{tabular}{|l|c|c|}
\hline \multicolumn{3}{|c|}{ Factors } \\
\hline & $\begin{array}{c}\text { Factor 4 (Perception and experience } \\
\text { of the DCS change) }\end{array}$ & $\begin{array}{c}\text { Factor 5 (Perceived nature of } \\
\text { the DCS change) }\end{array}$ \\
\hline Factor 6 (Treatment of Offenders) $=$ & +.664 & -.552 \\
\hline $\begin{array}{l}\text { Factor 7 (Perceived effectiveness of correctional } \\
\text { centers as rehabilitative institutions) }=\end{array}$ & +.543 & -.575 \\
\hline
\end{tabular}

Note: 1. Correlation scale (Table 5.19) used to determine the existence of a relationship.

2. The value of standardized estimates used to determine the magnitude of the relationship.

3. The null hypothesis is that the correlation coefficient is equal to zero $(r=0)$.

4. The alternative hypothesis is that the correlation coefficient is greater than zero $(r>0)$.

5. The plus or minus sign determines the direction of the relationship.

6 . The larger the coefficient of an IV, the larger the observed influence on the DV.

The following graph depicts the relationships among the two factors constituting the perception of the DCS change on one side, and the two variables constituting the status of the DCS change on the other.

Figure 5: Relationships among Latent Factors: Perception and Status of the DCS Change (Offenders)

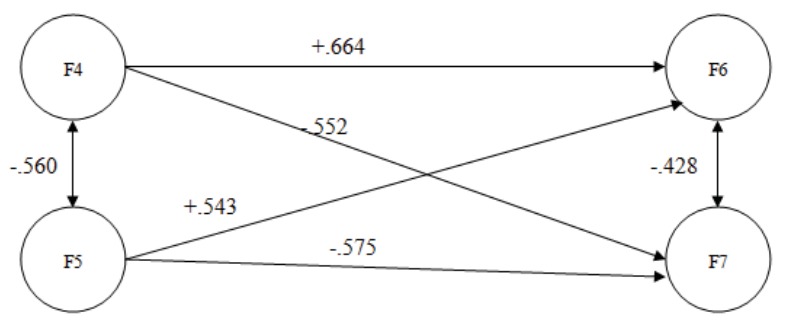

\subsubsection{Strength or magnitude of the relationship}

The relationship between perc-exp latent variable and treat-off is moderate and significant $(r=+.664)$. The relationship between perc-exp and perc-eff is also moderate and reliable $(r=-.552)$. Furthermore, the relationship between perc-nat on one hand, and treat-off and perc-eff on the other, is also moderate and reliable ( $r==.543$ and -.575 respectively). The magnitude of these relationships suggests that both latent variables of the perception of change exogenous variable have strong influence/effect on the status of change latent variables as a result of the moderate and reliable link between them. This is further reinforced by the strong linear link between the perception and experience of change and the perception of the nature of change in terms of correlation coefficient (-.560) and covariance coefficient (-.505).

\subsubsection{Statistical significance}

All the relationships between the perception of change latent variables and the status of change latent variables have been found to be statistically significant. The relationship between the perception and experience of change latent variable on one hand, and the treatment of offenders and the perceived effectiveness of correctional institutions as institutions of rehabilitation is as follows statistically: $(p=2.390$ and $t=-2.170)$ and $(p=2.119$ and $t=1.868)$. Furthermore, the relationship between the perception of the nature of change latent variable on one hand, and the treatment of offenders and the perceived effectiveness of correctional centers as institutions of rehabilitation latent variables on the other, has been found to be statistically significant too $(p=-2.548$ and $t=-2.584)$ and $(p=-2.373$ and $t=$ -2.320). And as such, the null hypothesis that there is no statistically significant relationship between offenders' perception of the DCS change and the status of the DCS change is discredited. The alternative hypothesis that there is a statistically significant relationship between offenders' perception of the DCS change (as an exogenous variable) and the status of the DCS change (as an endogenous variable) is upheld. 
Figure 6: Structural Model for Offenders: Perception of the DCS Change and the Status of the DCS Change

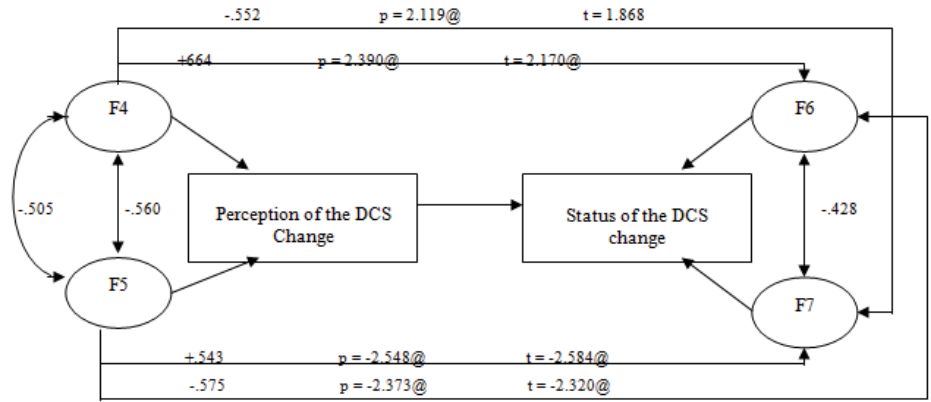

Note:

1. F4 = Perc-exp; F5 = Perc-nat; F6 $=$ Treat-off; F7 = Perc-eff.

2. Correlations significant at $p>01(t>2.56)$ or $p>.05(t>1.96)$ (Harrell, 2001).

3. The higher the correlation, the better the reliability.

4. A correlation of zero means that one variable cannot be predicted from the other without a large error.

5. The null hypothesis is equal to zero.

6. The alternative hypothesis is greater than zero.

7. A large correlation coefficient is significant.

8. Non-significant correlation means meaningless prediction of one variable from the other.

9. Significant correlation below .7: real but weak relationship with much error of prediction.

10. Significant correlation above .7: strong relationship with moderate error of prediction.

11. Significant correlation above .9: very strong relationship with good accuracy of prediction.

12. Reject null hypothesis if $p$-value is less than significance level $(p<t)$.

13. A small t-value and a big $p$-value means that there is no significant difference between null hypothesis and alternative hypothesis - non-significant relationship.

14. Big t-value and a small $p$-value means that there is significant difference between null hypothesis and alternative hypothesis - significant relationship.

15. Curved double-headed arrow represents covariation between latent variables.

16. Straight double headed arrow represents correlation between the two latent variables.

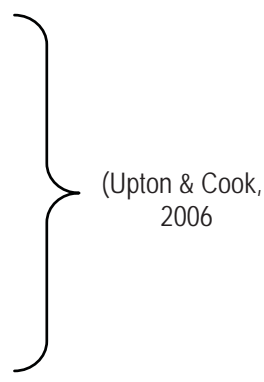

\subsubsection{Comparing and contrasting correctional officials' and offenders' perceived relationship between perception of the DCS change and status of the DCS change}

From Figure 4 and Figure 6 , it is clear that there are similarities and differences between correctional officials and offenders in terms of perceiving the nature of the DCS change from the perspective of the relationship and significance thereof between the latent variables of the perception of DCS change exogenous variable and the latent variables of the status of DCS change endogenous variable.

What is interesting to note from the perspective of the relationship between the perception of the DCS change and the status of the DCS change is that the perception and experience of change latent variable from both correctional officials' and offenders' sides exerts an influence on the status of DCS change through the latent variables concerned. The perception and experience of change latent variable from the sides of correctional officials and offenders has a significant and reliable relationship (by virtue of the size of the correlation coefficients but without taking into consideration the magnitude of the relationship) with the latent variables of the status of DCS change. For correctional officials, $r=.382$ and -.246 ; and for offenders, $r=+.664$ and -.552 . This is the first similarity. The second similarity lies in the fact that the perception and experience of change latent variable from the perspective of both correctional officials and offenders has a statistically significant relationship with the latent variables of the status of change endogenous variable. For correctional officials, $p=4.368$ and $t=4.129 ; p=-2.780$ and $t=-2.585$. For offenders, $p=2.390$ and $t=$ 2.170; $p=2.119$ and $t=1.868$. This is based on $t>1.96$ or 2.56 .

Taking into consideration the magnitude of the relationship, the perception and experience of change latent variable has the most influence or effect on the status of change latent variables, judging by the size of the correlation coefficient. As Upton \& Cook (2006) put it that the larger the correlation coefficient, the stronger the relationship. And the stronger the relationship, the more reliable the relationship. Based on this, the perception and experience of change latent variable from the side of offenders exerts a moderate and reliable relationship on the status of change latent 
variables. This is the first noticeable differences. The second difference is that the perception and experience of change latent variable from the side of correctional officials has a relationship with the status of DCS change variables which is higher in terms of statistical significance when compared to the relationship between the perception and experience of change latent variable and the status of DCs change latent variables from the side of offenders. The differences referred to above point to a very important finding that latent variables of the independent variable can individually influence the dependent variable through one or more of its latent variables significantly. These differences demonstrate the extent to which pairs of independent latent variables, though they are closely related in terms of covariance and correlation coefficients, are able to provide independent information for purposes of predicting the dependent variable.

On the perception and experience of the DCS change, there are areas of agreement between correctional officials and offenders. Both correctional officials and offenders agree that the DCS change was necessary for the continued success and effectiveness of the Department of Correctional Services; that the DCS change is supported by all interest groups (stakeholders); and that the DCS change is guided by an ethical code. However, on the perceived nature of change (type of change) factor, there are fundamental differences between correctional officials' and offenders' perceptions of the DCS change. The only agreements that are worth noting are in the area of the commencement of the DCS change, where both groups agree that the DCS change started and unfolded very slowly, as well as the aspect of human dignity, where both correctional officials and offenders agree that the DCS change demonstrates respect for human dignity. Other than these two, offenders, who are the recipients of the rehabilitation programmes and services, disagree with the correctional officials that the DCS change is a generally orderly, comprehensive and well managed type of change which has changed a lot within the Department of Correctional Services at correctional centre level. For the offenders, the DCS change process is generally chaotic due to its poor management; that full implementation is taking longer than expected. This is the essence of the difference between the two subjects of the study.

\subsubsection{Concluding comments on the perceived relationship between perception of the DCS change and status of the DCS change (correctional officials and offenders)}

The presentation on comparing empirical findings regarding the perceived relationship between the perception of DCS change and the status of DCS change from the perspective of both correctional officials and offenders has highlighted that the perception vis-à-vis status of DCS change part of the measurement model is quite good and therefore should be retained. The perception of change is a good predictor of the status of change. This is based on the following: firstly that the lowest $\mathrm{R}^{2}$ value (standardized regression coefficient also referred to as the coefficient of determination) is +.091 (correctional officials' side of the perception of change vis-à-vis the status of change part). Talking about low $\mathrm{R}^{2}$ values, Di Fabio (1999) argues that the lowest $\mathrm{R}^{2}$ value of .46 is a reasonable value to obtain in behavioral science research. This suggests that the $\mathrm{R}^{2}$ value of +.091 (which is far above Di Fabio's .46 value) is reasonably acceptable. All the other $\mathrm{R}^{2}$ values are reasonably higher, thereby indicating that the perception part of the measurement model accounts for a larger proportion of the variance in the measured items.

Secondly that on top of being significant and reliable, the relationships between the perception of DCS change and the status of DCS change are also statistically significant. The lowest t-value (which was not statistically significant) was 1.868 from the side of the offenders. But it was also not far from $t>1.96$ ). This statistical significance means that the relationships observed between perception of change's latent variables and those of the status of change's latent variables would not have come about statistically if there were no relationships in the population of correctional officials and offenders from which the studied samples were drawn. What this suggests is that there can be no statistically significant relationship in the sample if there is no existence of a relationship in the population (Di Fabio, 1999; Gliner, Vaske \& Morgan, 2001).

What can also be inferred from interrogating and comparing the findings from the perspective of both correctional officials and offenders is that weak relationship and statistical significance can occur simultaneously (Fabio, 1999; Gliner, Vaske \& Morgan, 2001). For example, the relationship between the perception and experience of change latent variable and the orientation towards (and treatment of) offenders latent variable was weak/small/low at $r=-.246$. And yet the same relationship was found to be statistically significant at $p=-2.780$ and $t=-2.585$. This indicates that statistical significance has got absolutely nothing to do with the strength/magnitude of the relationship between two variables. One can therefore conclude by stating that the perception vis-à-vis status of change part of the measurement model appears sound for purposes of predicting the relationship between the perception of change and the status of change. 


\section{Implications for Organisations}

The empirical findings relating to the relationship between the perceptions of DCS transformational change on one hand, and the status of the DCS transformational change on the other, have the following implications:

- First, the findings point to the importance of striking a balance between the non-human factor and the human factor within the organizational setting insofar as the management of organisational change initiatives is concerned. This is so because the findings on the relationship between correctional officials' and offenders' perceptions of the DCS change and their perceived status of (that is, progress with) the DCS change have highlighted the importance of managing the human dimension as part of the overall management of change. The foregoing suggests that people's perceptions of change do influence or determine the status of change. This further denotes that without due recognition being given to the human element, success in the implementation of organizational change initiatives will and can never be realized. Underestimating the human element and the human potential is a major mistake by change strategists and change implementers (Kinsey, 2000).

- The other implication is that in considering the importance of the human dimension as a building block for the success of organisational change initiatives, managers, as implementers of change efforts, need to give due consideration to the importance of managing people's perceptions of change. It is people's perceptions that shape or influence the direction of change. Positive perceptions facilitate change, thereby leading to the success of change. Negative perceptions hinder or derail change, thereby leading to the failure of change (Seijts \& Roberts, 2011). Given the above, it means that managers who facilitate or manage people's perceptions properly do so for the good of their organizations in terms of ensuring the success of change initiatives. On the other hand, managers and organizations that ignore employees' perceptions of change do so at their own peril.

- Organisations that need to ensure improved business performance through the successful implementation of transformational change efforts should ensure the effective Imanagement of people's perceptions within the realm of organizational change process management (Seijts \& Roberts, 2011).

- Differences in terms of progress between the effectiveness of correctional centers as institutions of rehabilitation and the treatment of offenders suggest that there won't be any much headway in terms of transforming correctional centers into effective rehabilitative institutions unless there is improvement in the treatment of offenders by correctional officials. The treatment of offenders can only improve when the mindsets of correctional officials in terms of their perceptions of, and attitudes towards, the change are transformed. The foregoing implication further suggests that people's mindsets have a profound impact on progress with the change. The status of the fundamental change to rehabilitation is where it is currently due to correctional officials' mindsets which influence, in a very negative sense, their negative perceptions of, and attitudes towards, the DCS change. Negative mindsets have given rise to negative perceptions and attitudes, thereby impacting negatively on the treatment of offenders. This calls for managerial intervention. The implication is that if managers do not intervene with a view to taking employees on a journey of personal transition in order to change their mindsets, attitudes and perceptions about change, very little progress, if any, would be made in terms of implementing and institutionalizing organisational change efforts.

- It is on the basis of the importance of managerial intervention that Van Tonder (2004a) emphasises that employees would be able to find stability and security as persons in terms their perceptions and emotions if and when they are taken on a journey of personal transition based on their concerns and expectations. Subjecting individual employees to change in order to change their mindset is also reiterated by Anderson and Ackerman-Anderson (2001) who indicate that the transformation of the mindset is a prerequisite to sustained change in organisations. For Burke Warner (2002), leading the organization in a new direction through change means reshaping employees' view of the world. The same sentiments are also expressed by Miller (2004) who argues that due to the fact that organisational change is about people, nothing will significantly change if people, as individuals and as groups, do not change. Considering the above, the findings imply that people within organizations are the main source of organisational change failures, which in turn makes people an organisational change risk (Allen, Jimmieson, Bordia \& Irmer, 2007).

- Individual change has to serve as a precursor to organisational change. It is for the same reason that Tichy and Devanna (1990) emphasise that the success of organisational change resides more in individual rather than organisational dynamics. The success of organizational change depends largely on individual employees 
changing not only their behaviors, attitudes, beliefs and perceptions, but their mindsets as well. This would minimise resistance to organisational change initiatives, thereby facilitating the implementation of organisational change efforts.

\section{Conclusion}

The empirical findings presented in this paper point to the fact that the success of transformational change initiatives hinges on successful change at individual level. It was indicated earlier on that both the organization and change are about people and as such, change taking place in organizations is not only meaningless, but also not sustainable without people. This is so because change is perceived by people as part of being rooted in individual dynamics. For this reason, the transformation of the mindsets of those affected by the change, through being informed by people's perceptions of the change, holds the key to the successful implementation of change initiatives, particularly transformational change efforts..

\section{References}

Agboola, A.A. \& Salawu, R.O. (2011). Managing deviant behaviour and resistance to change. International Journal of Business and Management. 6(1), 235-242.

Aiken, C. \& Keller, S. (2009). The irrational side of change management. Organization Practice. Retrieved from: http://www.google.com on 24 April 2012.

Allen, J., Jimmieson, N.L., Bordia, P., \& Immer, B.E. (2007). Uncertainty during organisational change: Managing perceptions through communication. Journal of Change Management, 7(2), 187.

Alvesson, M. \& Svenningsson, S. (2008). Forundringnarbete I organisationer, Libes. Retrieved from: http://www.google.com on 16 July 2011.

Anderson, D. \& Ackerman-Anderson, L.S (2001). Beyond change management: Advanced strategies for today's transformational leaders. San Francisco: Jossey-Bass.

Anderson, D. \& Ackerman Anderson, L. (2012). Do your leaders have the mindset to succeed at transformation? Retrieved from: http://www.google.com on 12 July 2012.

Balogun, J. \& Hope Hailey, V. (2004). Exploring strategic change. $2^{\text {nd }}$ ed. London: Prentice Hall.

Bartlett, M.S. (1954). A note on the multiplying factors for various B approximations. Journal of the Royal Statistical Society, 16(Series B), 296-298.

Beer, M. \& Nohria, N. (2000). Cracking the code of change. Harvard Business Review, May-June, 133-141.

Bregman, P. (2009). How to counter resistance to change. Harvard Business Press. Retrieved from: http://www.google.com on 08 August 2012.

Brinier, R.B. \& Kiefer, T. (2005). Research into the Experience of Emotion at Work: Definitely Older, But are we any Wiser? In N.M. Ashkanasy, C. Hartel, \& W. Zerbe (Eds.), The effect of Affect in Organizational Settings - Research on Emotion in Organizations, Vol. 1, Oxford, UK: Elsevier/JAI Press.

Burke, Warner, W. (2002). Organization change. Theory and practice. Thousand Oaks: Sage Publications.

Burnes, B. (2004). Managing change: A strategic approach to organisational dynamics. $4^{\text {th }}$ ed. Harlow: Prentice Hall.

Choi, M., \& Ruona, W. (2011). Individual readiness for organizational change and its implications for human resource and organization development. Human Resource Development Review, 10 (1): 46-73.

Coetzee, C.J.H. \& Stanz, K.J. (2007). "Barriers-to-change" in a governmental service delivery type organisation. SA Journal of Industrial Psychology, 33 (2), 76-82

Cook, S., Macaulay, S., \& Coldicott, H. (2005). Change management excellence. Using the four intelligences for successful organizational change. Retrieved from: http://www.google.com on 04 May 2012.

Corbeau, J. \& Sijats, J. (2005). Case Study: Implementation of a change process within Smaland Airport. Vaxjo University

Decker, D., Wheeler, G.E., Johnson, J., \& Parsons, R.J. (2001). Effect of organisational change on the individual employee. The Health Care Manager, 19(4), 1.

Devos, G., Beulens, M., \& Bouckenooghe, D. (2007). "Contribution of Content, and Process to Understanding Openness to Organisational Change: Two Experimental Simulation Studies", The Journal of Social Psychology, 147 (6), 607-629.

Di Fabio, R. (1999). Significance of relationships. Journal of Orthopaedic and Sports Physical Therapy, 29 (10), 572-573

Eby, L.T., Adam, D.M., Russell, J.E.A., \& Gaby, S.H. (2000). Perceptions of organizational readiness for change: Factors related to employees' reactions to the implementation of team-based selling. Human Relations, 53(3), 419-442.

Gall, M.D., Gall, J.P. \& Borg, W.R. (2003). Educational research: An introduction. (7th ed). Boston: Allyn \& Bacon.

George, J.M. and Jones, G.R. (2001). Towards a process model of individual change in organizations, Human Relations, 54(4), pp. 419-444.

Hair, J. F., Anderson, R. E., Tatham, R.L. \& Black, W. C. (2003). Multivariate Data Analysis (5th ed.), India: Pearson Education.

Hair, J.F., Anderson, R.E., Tatham, R.L. \& Black, W.C. (2006). Multivariate data analysis. (6 $6^{\text {th }}$ ed.). Upper Saddle River, NJ: Prentice- 
Hall.

Hattingh, B. (2004). Ups and downs of mergers, acquisitions. Business Day, July 19, 1st ed. Retrieved from: http://www.google.com on 26 June 2011.

Imberman, M.D. (2009). Organizational change and organizational justice: Assessing the impact on organizational commitment, changeoriented organizational citizenship behaviour, and attitude toward future change. PhD Dissertation. ProQuest Dissertations and Theses, 2011/09/08, Alliant International University, Los Angeles, California.

Judge, T.A., Thoresen, C.J., Pucik, V., \& Welbourne, T.M. (1999). Managerial coping with organisational change: A dispositional perspective. Journal of Applied Psychology, 84 (1), 107-122.

Kaiser, H.F. (1970). A second generation Little Jiffy. Psychometrika, 35, 401-415.

Kerlinger, F. (1992). Foundations of behavioural research. Florida: Harcourt Brace College Publishers.

Kiefer, T. and R.B. Briner (2006). 'Emotions at work: Implications for International Business and Management' in P.R. Jackson and M. Shams (eds) International Business and Management: Developments in Work and Organizational Psychology 20 - Implications for International Business. Elsevier.

Kinsey, C. (2000). The biggest mistakes in managing change. Innovative Leader. 9(12).

Kohurt, A.M. (2010). Significant workplace change: Perspectives of survivors. D.Ed Dissertation. Northern Illinois University, Dekalb, Illinois.

Lotich, P. (2011). Why do organizational change efforts often fail? Thriving Small Business. Retrieved from http://www.projectmanagement-com.info/douglas-mcgregor-human-side-of-enterprise/ on 23 September 2011.

Miller, D. (2004). Building sustainable change capability. Industrial and Commercial Training, 36 (1), 9-12.

Mourier, P. \& Smith, M. (2001). Conquering organisational change: How to succeed where most companies fail. Atlanta: CEP Press.

Nelissen, N.J.M \& Scheepers, P.L.H. (1992). Ecological consciousness and behaviour examined: An empirical study in the Netherlands. Social Wetenschappen, 35 (4), 64-81.

Nguyen and Kleiner (2003). The effective management of mergers. Leadership \& Organizational Development Journal, 24(7/8), 447455.

Palmer, I, Dunford, R \& Akin, G. (2009). Managing organizational change: A multiple perspectives approach. $2^{\text {nd }}$ ed. New York: McGraw-Hill/Irwin.

Plant, R. (1987). Managing change and making it stick. Aldershot: Gower Publishing Co.

Puplampu, B.B. (2005). "Towards a framework for understanding the distressed organization: Insights from practitioner-based organizational interventions in an emerging economy". Consulting Psychology Journal: Practice and Research, 57 (4), $246-258$.

Refferty, A.E. \& Griffin, M.A. (2006). Perceptions of organisational change: A stress and coping perspective. Journal of Applied Psychology, September, 91(5), 1154.

Rodda, J. (2007). A multilevel examination of employee reactions to organizational change. PhD Dissertation. DePaul University, Chicago.

Saurina, C. \& Coenders, G. (2002). Predicting overall service quality. A structural equation modelling approach. Developments in Social Science Methodology.

Seijts, G.H. \& Roberts, M. (2011). The impact of employee perceptions on change in a municipal government. Leadership and Organization Development Journal, 32 (2), 190-213.

Smith, J.W. (2009). The human side of change: Towards a pragmatic, evolutionary conception of cognition and emotion in organizational change. PhD Dissertation. Virginia Commonwealth University.

Smollan, R.K. (2006). Minds, hearts and deeds: Cognitive, affective and behavioural responses to change. Journal of Change Management, 6 (2), 143-158.

Social Media Directory. (2011). Managing change in the public sector. London. Dated 29 March 2011. Retrieved from: http://www.google.com on 30 August 2010.

Tabachnick, B. \& Fidell, L. (2007). Using multivariate statistics. (5 $5^{\text {th }}$ ed). Boston: Allyn \& Bacon.

Todnem, R. (2007). Ready or not ... Journal of Change Management, 7(1), 3-11.

Tredoux, C.G. \& Durrheim, K.W. (2002). Numbers, hypotheses and conclusions. Cape Town: Juta.

Turner, D. (2011). The paradox of change management. Turner Change Management Inc. Dated 30 July 2011. Retrieved from: http://www.google.com on 16 July 2011.

Turner, D-M., Hallencreutz, J. \& Haley, H. (2009). Leveraging the value of an organizational change management methodology. 9th International Conference on Knowledge, Culture and Change in Boston. The International Journal of Knowledge, Culture and Change Management, 9 (9), 1-34.

Upton, G. \& Cook, I (2006). Oxford dictionary of statistics. (2nd ed.). Oxford University Press. Retrieved from "http://en.wikipedia.org/wiki/Association (Statistics) - 2011/04/05.

Ursiny, T. \& Kay, B.A. (2007). The top performer' guide to change. Napierville: Sourcebooks, Inc.

Van Tonder, C.L. (2004a). Organisational change: Theory and practice. Pretoria: Van Schaik.

Van Tonder, C.L. (2004b). Organisational Development - Purposefully engaging change, Part I. Management Today, 20(10)/Yearbook 2005, 51-53, 57.

Van Tonder, C.L. (2004c). The march of time and the "evolution" of change. SA Journal of Industrial Psychology, 30 (3), $41-52$.

Van Tonder, C.L. (2005a). Complex, chaotic and catastrophic: The advent of nonlinear change. 5th International Conference on Knowledge, culture and change in Organisations, Rhodes, Greece, 19-22 July. 
Van Tonder, C. (2005b). Organisational development: purposefully engaging change. Part II. Management Today, 2 (10), $51-53,57$.

Van Tonder, C.L. (2006). Change risk and ignorance: Attempting to cross chasms in small steps. SA Journal of Human Resource Management, 4 (3), 1-11.

Van Tonder, C.L. (2008). Stacking the dominoes... courting catastrophe at the "edge-of-chaos". Proceedings of the 9th IFSAM World Management Conference, Shanghai, People's Republic of China, 26-28 July.

Van Tonder, C.L. (2009). Organization identity as managerial concern. In N. Delener, L. Fuxman, F. Victor Lu, A. Putnova \& L.E. RiveraSolis (Eds.), Readings book: Eleventh International Conference of the Global Business and Technology Association(GBATA), 1171-1177.

Vas, A. \& Lejeune, C. (2004). Revisiting resistance to change at the university: An interpretative approach. Working Paper. Center for Research in Change, Innovation and Strategy.

Wharton Executive Education. (2011). Harnessing fire: Managing emotions for successful organizational change. Wharton@work. ENewsletter for the Aresty Institute of Executive Education. 